\title{
BMJ Open Prevalence and incidence of type 1 diabetes in Ireland: a retrospective cross-sectional study using a national pharmacy claims data from 2016
}

\author{
Katarzyna Anna Gajewska (D) , ${ }^{1}$ Regien Biesma (D) , ${ }^{2}$ Seamus Sreenan (D) ,3,4 \\ Kathleen Bennett (i) ${ }^{1}$
}

To cite: Gajewska KA, Biesma R, Sreenan S, et al. Prevalence and incidence of type 1 diabetes in Ireland: a retrospective cross-sectional study using a national pharmacy claims data from 2016. BMJ Open 2020;10:e032916. doi:10.1136/ bmjopen-2019-032916

- Prepublication history and additional material for this paper are available online. To view these files, please visit the journal online (http://dx.doi org/10.1136/bmjopen-2019032916).

Received 11 July 2019 Revised 06 December 2019 Accepted 07 January 2020

Check for updates

(C) Author(s) (or their employer(s)) 2020. Re-use permitted under CC BY-NC. No commercial re-use. See rights and permissions. Published by BMJ.

${ }^{1}$ Division of Population Health Sciences, Royal College of Surgeons in Ireland, Dublin, Ireland

${ }^{2}$ Global Health Unit, Department of Health Sciences, University Medical Centre Groningen, Groningen, The Netherlands ${ }^{3} 3$ U Diabetes, Royal College of Surgeons in Ireland, Dublin, Ireland

${ }^{4}$ Department of Diabetes and Endocrinology, Connolly Hospital Blanchardstown, Blanchardstown, Dublin, Ireland

Correspondence to Katarzyna Anna Gajewska; katarzynagajewska@rcsi.ie

\section{ABSTRACT}

Objectives The aim of this study is to estimate the prevalence and incidence of type 1 diabetes in the Irish population using a national pharmacy claims database in the absence of a national diabetes register.

Design National, population-based, retrospective, crosssectional study.

Setting Community care with data available through the Health Service Executive Pharmacy Claims Reimbursement Scheme from 2011 to 2016.

Participants Individuals with type 1 diabetes were identified by coprescription of insulin and glucometer test strips without any prolonged course ( $>12$ months) of oral hypoglycaemic agents prior to commencing insulin. Those claiming prescriptions for long-acting insulin only, without any prandial insulin, were excluded from the analysis. Incidence was estimated based on the first claim for insulin in 2016, with no insulin use in the preceding 12 months.

Main outcome measures Prevalence of type 1 diabetes in children ( $<18$ years) and adults ( $\geq 18$ years); incidence of type 1 diabetes in children ( $\leq 14$ years) and adolescents and adults ( $>14$ years).

Results There were 20081 prevalent cases of type 1 diabetes in 2016. The crude prevalence was $0.42 \%$ (95\% Cl $0.42 \%$ to $0.43 \%$ ). Most prevalent cases ( $n=17053,85 \%)$ were in adults with a prevalence of $0.48 \%$ (95\% Cl $0.47 \%$ to $0.48 \%$ ). There were 1527 new cases of type 1 diabetes in 2016, giving an incidence rate of 32 per 100000 population/ year $(95 \% \mathrm{Cl} 30.5$ to 33.7$)$. There was a significant positive linear trend for age, for prevalence $(p<0.0001)$ and incidence $(p=0.014)$. The prevalence and incidence were 1.2-fold and 1.3-fold higher in men than women, respectively. Significant variations in prevalence $(p<0.0001)$ and incidence $(p<0.001)$ between the different geographical regions were observed. Conclusions This study provides epidemiological estimates of type 1 diabetes across age groups in Ireland, with the majority of prevalent cases in adults. Establishing a national diabetes register is essential to enable updated epidemiological estimates of diabetes and for planning of services in Ireland.

\section{INTRODUCTION}

The prevalence and incidence of diabetes is increasing worldwide. In 2017, the
Strengths and limitations of this study

This is a national population-based study based on objective pharmacy claims data.

- Epidemiological data on the prevalence and incidence of type 1 diabetes in Ireland are limited, and this study provides important information for national resource planning and for comparison with international studies.

Data across all age groups were included in contrast to previous studies focused only on paediatric type 1 diabetes.

The study is limited by the duration of only 6 years of continuous data on pharmacy claims and by the lack of external validation due to the absence of a national diabetes register in Ireland.

International Diabetes Federation estimated that there were 425 million adults aged 20-79 years with diabetes (all types). ${ }^{1}$ The pathophysiology of type 1 diabetes is different from type 2 diabetes: it is an autoimmune condition, characterised by destruction of pancreatic beta cells, resulting in absolute insulin deficiency, whereas type 2 diabetes is characterised by a combination of insulin resistance and inadequate insulin secretion to meet the body's needs. ${ }^{2}$ Type 2 diabetes accounts for the vast majority of cases while type 1 diabetes accounts for approximately $5 \%-10 \%$ of the total population of people with diabetes. ${ }^{2}$ The epidemiology of type 1 diabetes is, however, best described in children aged $\leq 14$ years of age $^{2}$ through three international populationbased studies: DIAMOND Project, EURODIAB and the SEARCH for Diabetes in Youth, ${ }^{3-6}$ and the incidence is increasing by approximately $3 \%$ (or more) a year. ${ }^{7}$

The paucity of data available on incidence and prevalence of type 1 diabetes in adults was highlighted in a recent systematic review on this topic. ${ }^{5}$ Information on adult type 
1 diabetes (including adolescents aged $>14$ years) was provided in only 35 countries, whereas information on paediatric diabetes (children aged 14 years and under) was available in 88 countries. ${ }^{5}$ Although type 1 diabetes has traditionally been called 'juvenile diabetes' and considered as a disease of childhood, recent evidence suggests that it presents in adults more commonly than previously believed. ${ }^{2}$ Approximately one quarter of those with type 1 diabetes are diagnosed as adults, ${ }^{4}$ and adults aged $\geq 20$ years account for more than a million people ( $85 \%$ of the total) with type 1 diabetes in the USA. ${ }^{8}$ Similarly, analysis of 60 years of data in the UK Biobank suggests that as many as half of all incident cases of type 1 diabetes were diagnosed in adulthood. ${ }^{9}$ Incidence rates in adult populations are rarely available, in part due to the difficulty in distinguishing type 1 diabetes from type 2 diabetes requiring insulin treatment. ${ }^{5}$ In addition, more than $20 \%$ of adults with type 2 diabetes may also be receiving insulin. ${ }^{10}$

Although evidence is scarce, of those studies available prevalence and incidence of type 1 diabetes have usually been based on data from national (eg, UK and Denmark $)^{11} 12$ or local (eg, Italy $)^{13}$ diabetes registries, national surveys (eg, Canada and Scotland) ${ }^{14} 15$ or hospital/GP records (eg, Lithuania and Iraq) ${ }^{16-18}$ Use of medication or claims data is relatively uncommon. In a systematic review of the incidence of type 1 diabetes in people aged $\leq 34$ years, only $13 \%$ of the 71 reviewed articles used drug registries to obtain epidemiological data. ${ }^{5}$ Currently, there is no diabetes register in Ireland, and previously only two studies have examined the prevalence of type 1 diabetes in adults: one was based on a survey of Irish diabetes clinics (self-reports), ${ }^{19}{ }^{20}$ and the other on a mathematical model, ${ }^{21}$ but both with limitations to study design and approach taken. In addition, although a systematic review on the prevalence of diabetes in the adult population in Ireland was published recently, studies focused solely on type 1 diabetes were excluded. ${ }^{22}$ According to this systematic review, the overall prevalence of adult diabetes in Ireland was $5.2 \%$ in 2015 , but there was no differentiation between type 1 and type 2 diabetes. ${ }^{22}$ The aim of this study is to estimate the prevalence and incidence of type 1 diabetes in the Irish population across all ages using a national pharmacy claims database.

\section{METHODS}

A retrospective cross-sectional study was conducted using the Irish Health Service Executive Primary Care Reimbursement Service (HSE-PCRS) national pharmacy claims database from the years 2011-2016.

\section{Settings/data sources}

The HSE-PCRS pharmacy claims database is primarily for administrative purposes and collates basic demographic information and details on monthly dispensed medications from the main community drug schemes including the Drug Payment (DP), General Medical Services (GMS) and Long-Term Illness (LTI) schemes. ${ }^{23}$ The DP scheme provides medicines to all Irish residents not covered by either the GMS or LTI schemes. There was a monthly out-of-pocket cost per family of up to $€ 144$ per month (at the time of the study). The GMS scheme ('medical card') is based on means and age; the means testing is based on the weekly income threshold and increased for those aged over 70 years ${ }^{23} 24$ with a small copayment applied to each item. ${ }^{23}$ The LTI scheme does not include means testing and provides free medication for 16 specified chronic illnesses including diabetes. ${ }^{23}{ }^{25}$ Patients with diabetes under the LTI scheme have their medicinesrelated costs fully covered by the state (including insulin, oral hypoglycaemic agents (OHAs), glucometer test strips, needles, infusion sets and so on); therefore, they have no medicine-related out-of-pocket expenses.

All prescription items in the HSE-PCRS pharmacy claims database are coded using the WHO's Anatomical Therapeutic Chemical (ATC) classification, ${ }^{26}$ and the database contains basic demographic information including age, sex and region of residence. ${ }^{27}$ The HSE-PCRS database has previously been used to investigate type 2 diabetesrelated prescriptions. ${ }^{27}$

\section{Study population}

The study population consists of all those with diabetes who were eligible for inclusion in the GMS and LTI schemes and who received at least one prescription for medication for diabetes, according to the WHO ATC codes for diabetes $(\mathrm{A} 10)^{26}$ in years 2011-2016. As the financial burden of diabetes-related medicines is significant in Ireland, all those who receive their diabetes care (either through the primary care or hospital diabetes clinics) are advised to apply for either the LTI or GMS scheme from their initial visit. Therefore, we assume that these schemes cover the entire population with diabetes who have been prescribed and dispensed the diabetesrelated medicines in Ireland.

\section{Ethical approval}

The data are all anonymised and permission was obtained from the data controllers (HSE-PCRS) for use of the data. As it was a secondary data analysis of a fully anonymised dataset, ethical approval was not required.

\section{Patient and public involvement}

No patients or the public were involved in the study protocol design, the specific aims or research questions development, or in developing plans for recruitment, design, or implementation of the study. No patients were asked to advise on interpretation or writing.

\section{Definitions}

To differentiate type 1 from other types of diabetes, we used case definition criteria based on the review of existing definitions and algorithms ${ }^{2-35}$ and available clinical guidelines for type 1 diabetes treatment. None of the existing algorithms were suitable to use in the Irish 


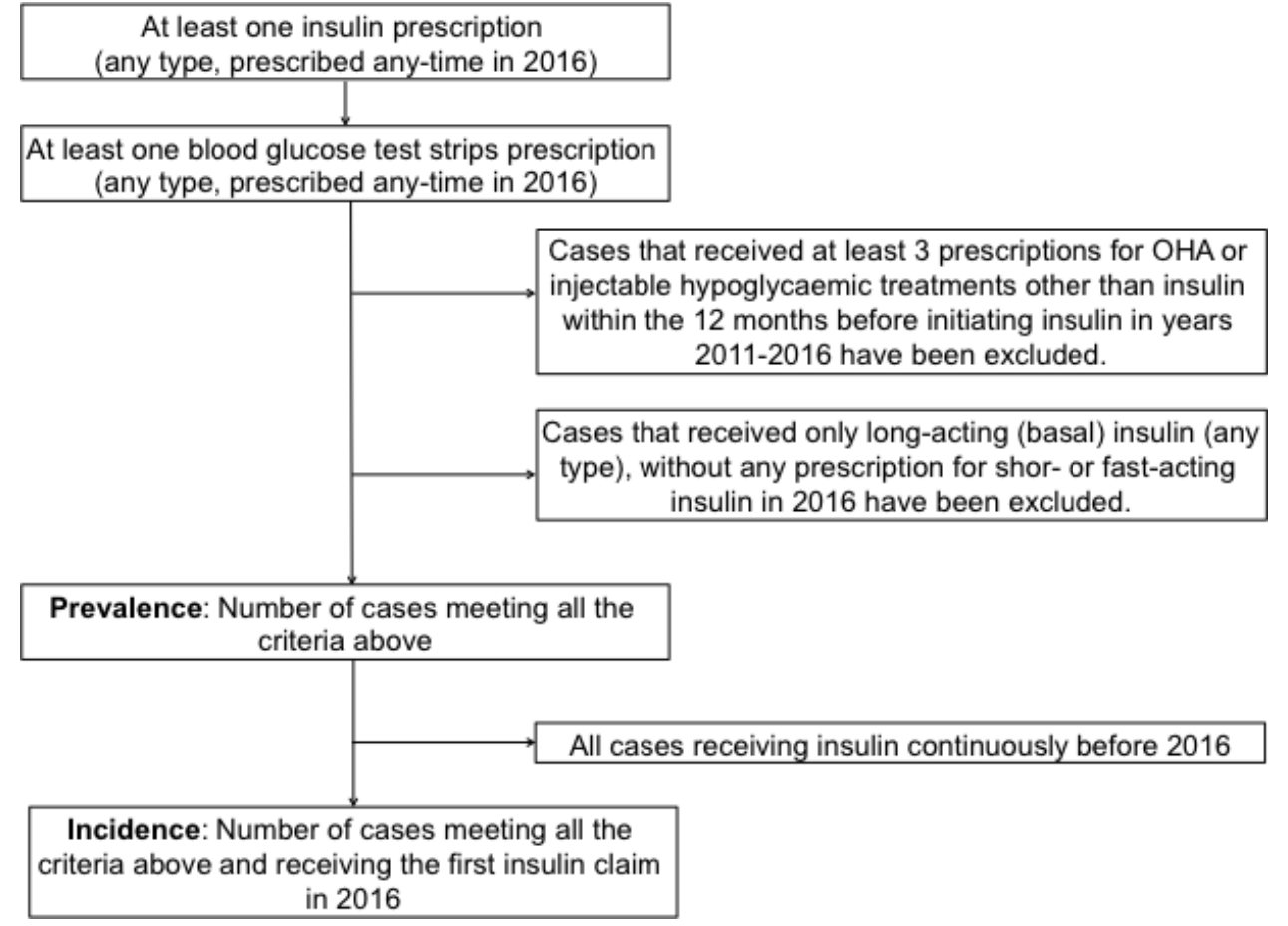

Figure 1 Flow chart presenting the definition of the prevalent and incident cases of type 1 diabetes based on the pharmacy claims database. OHA, oral hypoglycaemic agent.

context for a variety of reasons. We decided to focus on clinical guidelines and type 1 diabetes specific treatment and use a Klompas's algorithm as a guide. ${ }^{34}$ This algorithm helps to identify type 1 diabetes from type 2 diabetes based on chart review and different inclusion (insulin, urine test strips and glucagon) and exclusion criteria (OHA, excluding metformin). As no official guidelines existed for the treatment of type 1 diabetes in Ireland at the time of the study, we used the American Diabetes Association ${ }^{36}$ and the UK National Institute for Health and Care Excellence (NICE) guidelines. ${ }^{37}$ Initial analyses of different definitions and the use of a very detailed, and prescription-based, Klompas's algorithm ${ }^{34}$ guided us to use insulin and blood glucose test strips only and to exclude people on prolonged treatment of OHA prior to commencing insulin. We also excluded those patients receiving prescriptions for long-acting (basal) insulin only, without any prescription for prandial insulin, as these people are more likely to have type 2 diabetes than type 1 diabetes. ${ }^{38}{ }^{39}$ After initial analysis of different definitions based on the type 1 diabetes specific treatment schemes (online supplementary table 1), algorithms (online supplementary table 2) and comparisons with other existing evidence, ${ }^{28-35}$ the following definition was used (see figure 1).

\section{Statistical analysis}

Data analysis included descriptive statistics (proportions or percentages) with $95 \%$ CIs where appropriate. Crude number and rates of incident and prevalent cases in 2016 are presented and stratified by age groups $(0-14,15-24$, 25-34, 35-44, 45-54, 55-64, 65-74 and 75+ years), region of residence and gender. In addition, the prevalence was calculated for individuals under 18 years (children and adolescents) and for adults (aged 18 years and over), and incidence was calculated for children up to (and including) 14 years and adults and adolescents 15 years and over to allow international comparison with existing evidence. The 2016 Central Statistics Office (www.cso. ie) data were used for the calculation of age-specific rates (denominators for population numbers), and the overall prevalence and incidence rates for the population were age standardised to the European standard population for international comparison. ${ }^{40} \chi^{2}$ tests were used to compare differences in prevalence for age (CochranArmitage trend test was used for linear trend), region and gender. Negative binomial regression was used to compare incidence rate across age, region and gender. Significance at $\mathrm{p}<0.05$ was assumed. SAS statistical software (V.9.4) and Microsoft Excel for Mac 2011 were used for analysis.

\section{RESULTS}

\section{Prevalence}

A total of 20081 individuals met the definition for prevalent type 1 diabetes in 2016 in Ireland providing an overall crude population prevalence of $0.42 \%(95 \%$ CI $0.42 \%$ to $0.43 \%$ ). The crude prevalence rate was significantly lower in those $<18$ years of age compared with adults aged 18 years and over (table 1 ). The agestandardised prevalence rate for the population was $0.45 \%(95 \%$ CI $0.44 \%$ to $0.46 \%)$. The prevalence 
Table 1 Prevalence of type 1 diabetes in the Irish population in 2016 stratified by age group

\begin{tabular}{|c|c|c|c|c|}
\hline Age group & Prevalent cases & $\begin{array}{l}\text { Population } \\
\text { (Census 2016) }\end{array}$ & Prevalence (\%) & $95 \% \mathrm{Cl}(\%)$ \\
\hline $0-14^{*}$ & 1846 & 1006552 & $0.18^{*}$ & 0.18 to 0.19 \\
\hline $15-24^{*}$ & 2182 & 576452 & $0.38^{*}$ & 0.36 to 0.39 \\
\hline $25-34^{*}$ & 2363 & 659410 & $0.36^{*}$ & 0.34 to 0.37 \\
\hline $35-44^{*}$ & 2831 & 746881 & $0.38^{*}$ & 0.37 to 0.39 \\
\hline $45-54^{*}$ & 2897 & 626045 & $0.46^{*}$ & 0.45 to 0.48 \\
\hline $55-64^{*}$ & 2889 & 508958 & $0.57^{\star}$ & 0.55 to 0.59 \\
\hline $65-74^{*}$ & 2688 & 373508 & $0.72^{*}$ & 0.69 to 0.75 \\
\hline $75+^{*}$ & 1948 & 264059 & $0.74^{*}$ & 0.71 to 0.77 \\
\hline Total - C†‡ & $20081 † \ddagger$ & 4761865 & $0.42 † \ddagger$ & 0.42 to 0.43 † \\
\hline Total - S†§ & $20081 † \S$ & 4761865 & $0.45+\S$ & 0.44 to 0.46 † \\
\hline$<18$ years 9 & 2591 & 1188242 & 0.229 & 0.21 to 0.23 व \\
\hline$\geq 18$ years $\emptyset$ & 17053 & 3573623 & $0.48 \emptyset$ & 0.47 to 0.48 व \\
\hline
\end{tabular}

${ }^{*}$ Significant increasing prevalence with age $\left(\chi^{2}=54.6, p<0.0001\right)$

†There were 437 missing data for age (2\%). The data are included in the total number of prevalent cases.

$\ddagger$ Total - C (crude): crude prevalence.

$\S$ Total - S (standardised): prevalence (\%) age-standardised to the European Standard Population 2013.

II Significant difference between $<18$ and $\geq 18$ years $\left(\chi^{2}=1500, p<0.001\right)$.

was significantly higher in men than women $0.46 \%$ vs $0.37 \%(\mathrm{p}<0.0001)$. Age-standardised prevalence of men and women was $0.51 \%$ and $0.39 \%$, respectively. Of all prevalent cases, $55 \%$ were men. The age-adjusted prevalence was the highest in the oldest age groups, and the lowest in children under $\leq 14$ years (table 1 ). There was a significant increasing prevalence with increasing age (table 1). Significant variation in prevalence between the different geographical regions was observed ranging from $0.34 \%$ to $0.56 \%\left(\chi^{2}=191.64, \mathrm{p}<0.0001\right)$ across all ages. There was a 2.5 -fold variation in the prevalence in those under 18 years between geographical regions (online supplementary table 3 ).

\section{Incidence}

There were 1527 incident cases, giving a crude incidence rate of 32.07 (95\% CI 30.46 to 33.68) per 100000 persons per year for the population (table 2 ). The age-standardised

Table 2 Number of new cases and incidence rate (per 100000 population per year) of type 1 diabetes in the Irish population in 2016

\begin{tabular}{|c|c|c|c|c|}
\hline Age group & Incident cases & Population (Census 2016) & $\begin{array}{l}\text { Incident rate per } 100000 \\
\text { population/year }\end{array}$ & $95 \% \mathrm{Cl}$ \\
\hline $0-14^{*}$ & 319 & 1006552 & $31.69^{*}$ & 28.21 to 35.17 \\
\hline $15-24^{*}$ & 155 & 576452 & $26.89^{\star}$ & 22.66 to 31.12 \\
\hline $25-34^{*}$ & 197 & 659410 & $29.88^{*}$ & 25.70 to 34.05 \\
\hline $35-44^{*}$ & 233 & 746881 & $31.20^{*}$ & 27.19 to 35.20 \\
\hline $45-54^{*}$ & 150 & 626045 & $23.96^{*}$ & 20.13 to 27.79 \\
\hline $55-64^{\star}$ & 152 & 508958 & $29.86^{*}$ & 25.12 to 34.61 \\
\hline $65-74^{*}$ & 154 & 373508 & $41.23^{*}$ & 34.72 to 47.74 \\
\hline $75+^{\star}$ & 143 & 264059 & $54.15^{*}$ & 45.28 to 63.03 \\
\hline TOTAL - C†‡ & $1527 \dagger \ddagger$ & 4761865 & $32.07 \dagger \ddagger$ & 30.46 to $33.68 \dagger \neq$ \\
\hline TOTAL - S†§ & $1527 \dagger \S$ & 4761865 & $32.56+\S$ & 30.92 to $34.19 \dagger \S$ \\
\hline$\leq 14$ years & 319 & 1006552 & 31.69 & 20.66 to 4273 \\
\hline$>14$ years & 1184 & 3755313 & 31.53 & 20.52 to 42.53 \\
\hline
\end{tabular}

${ }^{*}$ Significant increasing incidence with age $(\mathrm{p}=0.014)$.

†There were 24 missing data for age (2\%) for incidence. The data are included in the total number of incident cases.

$\ddagger$ Total - C (crude): crude prevalence.

§Total - S (standardised): incident rate per 100000 population/year, age-standardised to the European Standard Population 2013. 
incidence for the population was 32.56 (95\% CI 30.92 to 34.10) per 100000 persons per year.

There were significantly more incident cases in men $(\mathrm{n}=820)$ than in women $(\mathrm{n}=681)$ in 2016 , giving incidence rates of 34.83 versus 28.29 per 100000 population/ year, respectively $(\mathrm{p}=0.03)$. The age-standardised incidence was $36.37 / 100000$ population/year in men versus 28.80/100 000 population/year in women. Of all incident cases, $1184(78 \%)$ were in adults and adolescents aged $>14$ years, compared with $319(21 \%)$ in children aged $\leq 14$ years. The crude incidence rate was 31.69 for those aged $\leq 14$ years and 31.53 per 100000 persons / per year in those aged over 14 years but not significantly different (table 2). There was a significant increasing incidence with age. The highest incidence was observed in children aged $\leq 14$ years, adults aged 33-44 years and older adults aged 75 years and over (table 2). Significant variation in the incidence rates between different geographical regions was observed ranging from 22.86 to 53.54 per 100000 population per year across all ages $(\mathrm{p}<0.001)$. There was an almost fivefold regional variations observed in children aged $\leq 14$ years and more than twofold variation in adolescents and adults aged $>14$ years (online supplementary table 3 ).

\section{DISCUSSION}

Based on pharmacy claims data, this national study estimated the overall prevalence of type 1 diabetes in Ireland as $0.45 \%$, and it increases with age. The prevalence in adults was $0.48 \%$ with the highest number of prevalent cases being observed in the $45-54$ years age group. The prevalence was significantly higher in men than women $(0.51 \%$ vs $0.39 \%)$, giving a male-to-female ratio of 1.2 . The prevalence was also significantly higher in adults than children and adolescents under 18 years. The current study also estimated the incidence rate as 32.07 per 100000 population/year and was similar for both children and adolescents/adults. The incidence was also significantly higher in men than women in all age groups over 14 years of age. Significant variation was observed between different geographical regions.

To date, there are only two studies available against which to validate our findings in the adult population in Ireland. The most recent, a National Survey of Diabetes Care Delivery in Acute Hospitals ${ }^{19}{ }^{20}$ initially found that there were 19748 adults with type 1 diabetes in Ireland, and these data were used as estimates for the 'Adult type 1 diabetes mellitus' national clinical guidelines of care ${ }^{41}$ and budget impact analysis. ${ }^{19}$ These data, however, may not be accurate as only four of the 31 diabetes services provided actual figures, and others indicated that these were based on respondents' 'best estimates' $;{ }^{20}$ authors of the survey have not included these figures in their official final report. ${ }^{20}$ Another study conducted in 2005 to estimate the epidemiology of type 1 diabetes in Ireland was based on a model using reference rates from a study conducted in Wales in $1998^{21}$ and therefore was not considered comparable in 2016. Our findings bear comparison with other epidemiological evidence that exists in the paediatric population. ${ }^{42-44}$ The crude prevalence number $(n=2591)$ that we have estimated appears to be close to other prevalence estimates, for example, from the Paediatric Diabetes National Audit ( $\mathrm{n}=2632$ in 2013). ${ }^{42}{ }^{43}$ Findings from the Irish Childhood Diabetes National Register, which mainly focuses on the incidence rather than prevalence, ${ }^{44}$ suggest that the crude incidence rate in children aged $\leq 14$ years was 28.8 per 100000 population/year in 2013, compared with our estimate of 31.6 per 100000 population/year in 2016. This difference might reflect the trend of increasing incidence of type 1 diabetes by at least $3 \%$ per year in Europe. ${ }^{7}$

This study contributes information about incidence and prevalence of type 1 diabetes in people of all ages, including those aged $18-64$ years. ${ }^{5}$ It is interesting to note that $35 \%$ of incident cases were in the age group of 35-64 years, in line with a recently published study using the UK Biobank, showing that as many as $42 \%$ of type 1 diabetes cases may be diagnosed between 31 years and 60 years of age. ${ }^{9}$ Another study from the UK suggests that type 1 diabetes presenting in later life is often unrecognised or misdiagnosed as type 2 diabetes, despite the need to start insulin therapy soon after diagnosis. ${ }^{45}$ According to a study from Italy, there are peaks in the incidence of type 1 diabetes in different age groups, with the highest observed in children and adolescents under 15 years, then a significant decrease in age groups 15-29 years, followed by continuously increasing incidence from the age of 29-49 years. ${ }^{13}$ In that study, there were no data for older age groups, but our findings demonstrate a similar pattern across all the available comparable age groups.

The results of the current study show a gender distribution of prevalence and incidence of type 1 diabetes being more common in men than women, a finding that was also demonstrated by other studies. ${ }^{51316}$ According to a review on gender effect, ${ }^{46}$ the ratio of male to female in adult onset type 1 diabetes ranged from 1.30 to 2.15 , compared with a ratio of 1.2 in our study for both incidence and prevalence. However, this review only included ages up to 44 years, so is not directly comparable. According to a more recent analysis of the Swedish diabetes register, ${ }^{47}$ incidence by gender in those aged 40 years or older was equally distributed among men and women, what may reduce the overall male-to-female ratio.

The prevalence rates correspond with data on the prevalence in adults, for example, in the USA from 2016 to $17(0.5 \%$ prevalence of type 1 diabetes in adult Americans), ${ }^{48}$ but seem lower than in Scotland where a prevalence of type 1 diabetes of $0.6 \%$ for the whole population and $0.7 \%$ in adults was found. ${ }^{15}$ It is difficult to compare our findings with other international evidence as most previous studies were conducted in younger populations (children and young adults, and young adults). ${ }^{5}$ For example, in a Canadian study, only those diagnosed with type 1 diabetes under 30 years were considered ${ }^{30}$ and those under 40 years of age were included in a USA-based 
study. ${ }^{49}$ Other epidemiological studies intentionally focused on particular age groups, that is, 15-34 years in Lithuania $^{16}{ }^{17}$ under 34 years in Sweden ${ }^{35}$ and under 40 years in Iraq. ${ }^{18}$ In addition, the definition we used was more inclusive and based on real-world diabetes management, not related to insulin intake only: for example, our definition did not exclude patients currently on insulin and OHA (metformin). NICE guidelines $(2015)^{37}$ recommend adding metformin to insulin therapy 'if an adult with type 1 diabetes and a BMI of $25 \mathrm{~kg} / \mathrm{m}^{2}(\ldots)$ or above wants to improve their blood glucose control while minimising their effective insulin dose' ${ }^{37}$ According to findings from the German diabetes registry, as many as $25.5 \%$ of patients with type 1 diabetes presented with the metabolic syndrome (at least three criteria including body mass index $\left.>30 \mathrm{~kg} / \mathrm{m}^{2}\right) .{ }^{50}$ However, data on the prevalence of metformin use in adults with type 1 diabetes are currently lacking. ${ }^{50}$

The main strengths of this study include its populationbased, nationwide character and use of objective pharmacy claims data. Our study is the first study published since 2005 to present epidemiological evidence for adults with type 1 diabetes in Ireland and provides findings for the paediatric population that are comparable with the existing evidence. Therefore, we believe that the method we used to assess prevalence and incidence is currently the best available, in the absence of any local or national adult register in Ireland to use as a tool for validation. This study estimate the prevalence and incidence of type 1 diabetes in the entire population, not limited by age, providing useful information for national resource planning and for comparison with international studies. The definition criteria that we have used were based on other definitions, clinical guidelines and real-world diabetes management to be more inclusive to all, not only typical cases of type 1 diabetes. This study has some potential limitations. First, the analysis of the database was conducted over a relatively short timeframe (6 years, 2011-2016). Therefore, in calculating prevalence, we may have misclassified some type 2 diabetes cases as type 1 if they had prolonged metformin use and had already progressed to basalbolus insulin. Second, although the chosen definition of a person with type 1 diabetes was considered thorough and discussed with experts in the area (see Methods and online supplementary tables 1 and 2 for more details), some people may have been misclassified. Unlike other studies using pharmacy claims databases for epidemiological estimates, ${ }^{28}{ }^{35}$ we had no information (eg, ICD-10 (International Statistical Classification of Diseases and Related Health Problems) codes or laboratory results) to confirm the diagnosis of type 1 diabetes. Therefore, it was not possible to distinguish less prevalent types of diabetes, such as Latent Autoimmune Diabetes of Adulthood from type 1 or gestational diabetes treated with insulin. Due to this limitation, we were also unable to track comorbidities and acute illness conditions other than diabetes that require diabetes-specific medicines. Moreover, we were unable to validate the pharmacy claims data, that is, based on the capture-recapture method. ${ }^{35}$ The HSE-PCRS data are anonymised so that access to patients' individual electronic health data or hospital charts was not possible, and therefore, we could not confirm accuracy as was done in other studies. ${ }^{28} 3035$ Another limitation is the possibility of overestimation of type 1 diabetes in the older aged population, particularly those over 70 years, who may be eligible for both LTI and GMS schemes at the same time and may have been double-counted. This may help to explain the high incidence rate in the older aged population, which is higher, for example, in comparison with existing evidence on incidence rates in Scottish adults (ie, Scottish Diabetes Register 2017) ${ }^{15}$ When comparing with other international evidence or registries, our results appear consistent in the younger age groups. There are limited data on the incidence of type 1 diabetes in the adult population internationally against which to validate our findings.

Although our study has limitations, our findings provide supportive evidence that in a country without a national diabetes register or any other source of epidemiological data, routinely collected administrative pharmacy claims data may be a useful alternative to estimate the prevalence and incidence of conditions such as type 1 diabetes. Complete, national diabetes registries or pharmacy claims data are available only in some developed countries - in the majority of cases, databases are lacking (in particular in underdeveloped or developing countries), which might explain the scarcity of epidemiological evidence for type 1 diabetes in populations across all ages. However, in the absence of alternative sources of epidemiological data such as registries, which may be considered more reliable, prescribing or pharmacy claims data may provide useful information for health service users and policy makers. Our study also highlights the need to establish a national diabetes register to continuously monitor the prevalence and incidence of diabetes in Ireland, diabetes-related outcomes and their burden. ${ }^{51}$ Finally, the findings of this study support the recent statements of a higher incidence of late-onset type 1 diabetes than previously assumed, which may have important implications for clinical practice. There is a need to further investigate the epidemiology of type 1 diabetes in adults through both cross-sectional and longitudinal analyses using nationally available datasets, such as diabetes registries, surveys, audits or pharmacy claims data, which will also allow for international comparisons. To validate our findings, a diabetes register should be established or a different research approach, using biological markers (C-peptide levels or islet cell or GAD antibodies), should be conducted.

Twitter Katarzyna Anna Gajewska @kate_gajewska, Regien Biesma @Regienbb and Kathleen Bennett @pharmacoepircsi

Acknowledgements We would like to thank the Health Service Executive Primary Care Reimbursement Service for supply of the data.

Contributors All authors were responsible for drafting the article and revising it critically for important intellectual content. KAG contributed to the design of the study; the collection, analysis and interpretation of data; the writing of the report; 
and the decision to submit the article for publication. RB and SS contributed to the design of the study, the interpretation of data and the writing of the report and the decision to submit the article; KB contributed to the design of the study, the collection of data, the analysis and interpretation of data and the writing of the report and the decision to submit the article. All authors approved the version to be published.

Funding This research was funded by the Health Research Board SPHeRE/2013/1 as a part of the PhD programme. KB was funded by a Health Research Board Award (RL-15-1579).

Competing interests None declared.

Patient consent for publication Not required.

Provenance and peer review Not commissioned; externally peer reviewed.

Data availability statement Data may be obtained from a third party and are not publicly available. The pharmacy claims data are managed by the HSE Primary Care Reimbursement Services. They are not permitted to be reused after analysis is completed. The formal permission to access to HSE-PCRS data granted for a limited period of use (6 months).

Open access This is an open access article distributed in accordance with the Creative Commons Attribution Non Commercial (CC BY-NC 4.0) license, which permits others to distribute, remix, adapt, build upon this work non-commercially, and license their derivative works on different terms, provided the original work is properly cited, appropriate credit is given, any changes made indicated, and the use is non-commercial. See: http://creativecommons.org/licenses/by-nc/4.0/.

\section{ORCID iDs}

Katarzyna Anna Gajewska http://orcid.org/0000-0002-7536-0591

Regien Biesma http://orcid.org/0000-0002-5532-0242

Seamus Sreenan http://orcid.org/0000-0003-2457-2612

Kathleen Bennett http://orcid.org/0000-0002-2861-7665

\section{REFERENCES}

1 IDF. Diabetes atlas. 8th edn, 2017. http://www.diabetesatlas.org

2 Kyvik KO, Nystrom L, Gorus F, et al. The epidemiology of type 1 diabetes mellitus is not the same in young adults as in children. Diabetologia 2004;47:377-84.

3 Frese T, Sandholzer $\mathrm{H}$. The epidemiology of type 1 diabetes mellitus, 2013.

4 Maahs DM, West NA, Lawrence JM, et al. Epidemiology of type 1 diabetes. Endocrinol Metab Clin North Am 2010;39:481-97.

5 Diaz-Valencia PA, Bougnères P, Valleron A-J. Global epidemiology of type 1 diabetes in young adults and adults: a systematic review. BMC Public Health 2015;15:255.

6 Mayer-Davis EJ, Kahkoska AR, Jefferies C, et al. ISPAD clinical practice consensus guidelines 2018: definition, epidemiology, and classification of diabetes in children and adolescents. Pediatr Diabetes 2018;19 Suppl 27:7-19.

7 Patterson CC, Harjutsalo V, Rosenbauer J, et al. Trends and cyclical variation in the incidence of childhood type 1 diabetes in 26 European centres in the 25 year period 1989-2013: a multicentre prospective registration study. Diabetologia 2019;62:408-17.

8 Juvenile Diabetes Research Foundation. Facts: type 1 diabetes, 2011. Available: http://www2.jdrf.org/site/DocServer/KW-T1D_ Factsheet.pdf?docID=1024 [Accessed 13 Nov 2017].

9 Thomas NJ, Jones SE, Weedon MN, et al. Frequency and phenotype of type 1 diabetes in the first six decades of life: a cross-sectional, genetically stratified survival analysis from UK Biobank. Lancet Diabetes Endocrinol 2018;6:122-9.

10 Sharma M, Nazareth I, Petersen I. Trends in incidence, prevalence and prescribing in type 2 diabetes mellitus between 2000 and 2013 in primary care: a retrospective cohort study. BMJ Open 2016;6:e010210.

11 Diabetes UK. Diabetes in the UK 2012. key statistics on diabetes, 2012. Available: https://diabetes-resources-production.s3-eu-west-1. amazonaws.com/diabetes-storage/migration/pdf/Diabetes-in-theUK-2012.pdf [Accessed Apr 2012].

12 Jørgensen ME, Kristensen JK, Reventlov Husted G, et al. The Danish adult diabetes registry. Clin Epidemiol 2016;8:429-34.

13 Bruno G, Runzo C, Cavallo-Perin P, et al. Incidence of type 1 and type 2 diabetes in adults aged 30-49 years. Diabetes Care 2005;28:2613-9.

14 Dai S, Bienek A, Pelletier C, et al. Estimation of the prevalence of type 1 and type 2 diabetes among Canadian adults. Can J Diabetes 2012;36:S20.
15 McKnight JA. Scottish diabetes data group Scottish diabetes survey 2017, 2017. Available: http://www.diabetesinscotland.org.uk/ Publications/SDS\%202017.pdf

16 Ostrauskas R, Žalinkevičius R, Jurgevičienė N, et al. The incidence of type 1 diabetes mellitus among 15-34 years aged Lithuanian population: 18-year incidence study based on prospective databases. BMC Public Health 2011;11:813.

17 Ostrauskas $\mathrm{R}$. The prevalence of type 1 diabetes mellitus among adolescents and adults in Lithuania during 1991-2004. Medicina 2007;43:242-50.

18 Almahfoodh D, Alabbood M, Alali A, et al. Epidemiology of type 1 diabetes mellitus in Basrah, southern Iraq: a retrospective study. Diabetes Res Clin Pract 2017;133:104-8.

19 Royal College of Physicians of Ireland. Budget impact analysis - CG044. Type1 diabetes in adults guideline Royal College of physicians of Ireland, 2018. Available: https://rcpi-live-cdn.s3. amazonaws.com/wp-content/uploads/2017/12/Budget-ImpactAnalysis-\%E2\%80\%93-CG044-Type-I-diabetes-in-adults-guideline. pdf. [Accessed 7 Feb 2018].

20 O'Donnell M, Smyth N, Dinneen S. National survey of diabetes care delivery in acute hospitals. health service executive, 2018. Available: https://www.hse.ie/eng/about/who/cspd/ncps/diabetes/resources/ national-survey-of-diabetes-care-delivery-in-acute-hospitals-2018. pdf

21 Balanda KP, Jordan A, E M Making diabetes count. A systematic approach to estimating population prevalence on the island of Ireland in 2005. Dublin/Belfast: Institute of Public Health in Ireland 2006.

22 Tracey ML, Gilmartin M, O'Neill K, et al. Epidemiology of diabetes and complications among adults in the Republic of Ireland 19982015: a systematic review and meta-analysis. BMC Public Health 2016;16:132.

23 Sinnott SJ, Bennett K, Cahir C. Pharmacoepidemiology resources in Ireland-an introduction to pharmacy claims data. Eur J Clin Pharmacol 2017.

24 O'Shea M, Teeling M, Bennett K. The prevalence and ingredient cost of chronic comorbidity in the Irish elderly population with medication treated type 2 diabetes: a retrospective cross-sectional study using a national pharmacy claims database. BMC Health Serv Res 2013;13:23

25 Hayden J, Flood M, McNicholas F. Adhd in children: a path to free medicines. Ir J Med Sci 2016;185:171-5.

26 World Health Organization WCCfDSM. Who. collaborating centre for drug statistics methodology: anatomical therapeutic chemical (ATC) classification index. Oslo, Norway: The Norwegian Institute of Public Health, 2017. http://www.who.int/medicines/regulation/medicinessafety/about/collab-centres-norwegian/en/

27 Murphy ME, Bennett K, Fahey T, et al. Geographical variation in antidiabetic prescribing in Ireland in 2013 and 2014: a cross-sectional analysis. Fam Pract 2017;34:587-92.

28 Liatis S, Dafoulas GE, Kani C, et al. The prevalence and treatment patterns of diabetes in the Greek population based on real-world data from the nation-wide prescription database. Diabetes Res Clin Pract 2016;118:162-7.

29 Sinnott S-J, McHugh S, Whelton $\mathrm{H}$, et al. Estimating the prevalence and incidence of type 2 diabetes using population level pharmacy claims data: a cross-sectional study. BMJ Open Diabetes Res Care 2017;5:e000288.

$30 \mathrm{Ng} \mathrm{E}$, Dasgupta K, Johnson JA. An algorithm to differentiate diabetic respondents in the Canadian community health survey. Health Rep 2008;19:71-9.

31 Norhammar A, Bodegård J, Nyström T, et al. Incidence, prevalence and mortality of type 2 diabetes requiring glucose-lowering treatment, and associated risks of cardiovascular complications: a nationwide study in Sweden, 2006-2013. Diabetologia 2016;59:1692-701.

32 Renard LM, Bocquet V, Vidal-Trecan G, et al. An algorithm to identify patients with treated type 2 diabetes using medico-administrative data. BMC Med Inform Decis Mak 2011;11:1-7.

33 Maggini M, Da Cas R, Lunghi C, et al. Estimate of incidence and prevalence of type 1 diabetes using electronic drug prescription Archives. Diabetologia 2010;53:S142.

34 Schroeder EB, Donahoo WT, Goodrich GK, et al. Validation of an algorithm for identifying type 1 diabetes in adults based on electronic health record data. Pharmacoepidemiol Drug Saf 2018;27:1053-9.

35 Rawshani A, Landin-Olsson M, Svensson A-M, et al. The incidence of diabetes among 0-34 year olds in Sweden: new data and better methods. Diabetologia 2014;57:1375-81.

36 American Diabetes Association. American diabetes association standards of medical care in 2016. Diabetes Care 2016;39:1-112. 
37 National Institute for Health and Care Excellence. Type 1 diabetes in adults - diagnosis and management. NICE Guidelines, 2015. nice. org.uk/guidance/ng17

38 Nathan DM, Buse JB, Davidson MB, et al. Medical management of hyperglycemia in type 2 diabetes: a consensus algorithm for the initiation and adjustment of therapy: a consensus statement of the American diabetes association and the European association for the study of diabetes. Diabetes Care 2009;32:193-203.

39 Inzucchi SE, Bergenstal RM, Buse JB, et al. Management of hyperglycemia in type 2 diabetes: a patient-centered approach: position statement of the American diabetes association (ADA) and the European association for the study of diabetes (EASD). Diabetes Care 2012;35:1364-79.

40 Eurostat. Revision of the European standard population. Eurostat European Commission, 2013. Available: https://ec.europa.eu/ eurostat/documents/3859598/5926869/KS-RA-13-028-EN.PDF/ e713fa79-1add-44e8-b23d-5e8fa09b3f8f

41 Department of Health. Adult type 1 diabetes mellitus. (NCEC national clinical guideline No. 17. Ireland, 2018.

42 O'Riordan S, Turner G, Browne C, Paediatric Diabetes Working Group. Model of care for all children and young people with type 1 diabetes. Health Service Executive, 2015.

43 Hawkes CP, Murphy NP. Paediatric type 1 diabetes in Ireland--results of the first national audit. Ir Med J 2014;107:102-4.
44 Roche EF, McKenna AM, Ryder KJ, et al. Is the incidence of type 1 diabetes in children and adolescents stabilising? The first 6 years of a National Register. Eur J Pediatr 2016;175:1913-9.

45 Thomas NJ, Lynam AL, Hill AV, et al. Type 1 diabetes defined by severe insulin deficiency occurs after 30 years of age and is commonly treated as type 2 diabetes. Diabetologia 2019;62:1167-72.

46 Gale EA, Gillespie KM. Diabetes and gender. Diabetologia 2001;44:3-15.

47 Wändell PE, Carlsson AC. Time trends and gender differences in incidence and prevalence of type 1 diabetes in Sweden. Curr Diabetes Rev 2013;9:342-9.

$48 \mathrm{Xu}$ G, Liu B, Sun Y, et al. Prevalence of diagnosed type 1 and type 2 diabetes among US adults in 2016 and 2017: population based study. BMJ 2018;362:k1497.

49 Menke A, Orchard TJ, Imperatore G, et al. The prevalence of type 1 diabetes in the United States. Epidemiology 2013;24:773-4.

50 Merger SR, Kerner W, Stadler M, et al. Prevalence and comorbidities of double diabetes. Diabetes Res Clin Pract 2016;119:48-56.

51 Irish Medical Times. National diabetes register is 'essential' to providing chronic disease management, 2017. Available: https:// www.imt.ie/news/national-diabetes-register-is-essential-toproviding-chronic-disease-management-25-01-2017/ [Accessed 19 Feb 2018]. 